\title{
Review
}

\section{Diagnostic Utility of Auto-Antibodies in Inflammatory Muscle Diseases}

\author{
Y. Allenbach ${ }^{\mathrm{a}, \mathrm{b}}$ and O. Benveniste ${ }^{\mathrm{a}, \mathrm{b}, *}$ \\ ${ }^{a}$ Assistance Publique - Hôpitaux de Paris, Pitié-Salpêtrière University Hospital, Department of Internal Medicine \\ and Clinical Immunology (DHU i2B), Paris, France \\ ${ }^{\mathrm{b}}$ Sorbonne Universités, Université Pierre et Marie-Curie Paris 6, Center of Research in Myology; UMR 974; Inserm, \\ U974, Paris, France
}

\begin{abstract}
To date, there are four main groups of idiopathic inflammatory myopathies (IIM): polymyositis (PM), dermatomyositis (DM), immune-mediated necrotizing myopathy (IMNM) and sporadic inclusion body myositis; based on clinical presentation and muscle pathology. Nevertheless, important phenotypical differences (either muscular and/or extra-muscular manifestations) within a group persist. In recent years, the titration of different myositis-specific (or associated) auto-antibodies as a diagnostic tool has increased. This is an important step forward since it may facilitate, at a viable cost, the differential diagnosis between IIM and other myopathies. We have now routine access to assays for the detection of different antibodies. For example, IMNM are related to the presence of anti-SRP or anti-HMGCR. PM is associated with anti-synthetase antibodies (anti-Jo-1, PL-7, PL-12, OJ, and EJ) and DM with anti-Mi-2, anti-SAE, anti-TIF-1- $\gamma$ and anti-NXP2 (both associated with cancer) or anti-MDA5 antibodies (associated with interstitial lung disease). Today, over 30 myositis specific and associated antibodies have been characterised, and all groups of myositis may present one of those auto-antibodies. Most of them allow identification of homogenous patient groups, more precisely than the classical international classifications of myositis. This implies that classification criteria could be modified accordingly, since these auto-antibodies delineate groups of patients suffering from myositis with consistent clinical phenotype (muscular and extra-muscular manifestations), common prognostic (cancer association, presence of interstitial lung disease, mortality and risk of relapse) and treatment responses. Nevertheless, since numerous auto-antibodies have been recently characterised, the exact prevalence of myositis specific antibodies remains to be documented, and research of new auto-antibodies in the remaining seronegative group is still needed.
\end{abstract}

Keywords: Myositis, polymyositis, dermatomyositis, idiopathic inflammatory myopathy, auto-antibody

\section{INTRODUCTION}

They are four main groups of idiopathic inflammatory myopathies (IIM): polymyositis (PM), dermatomyositis (DM), immune-mediated necrotizing myopathy (IMNM) and sporadic inclusion body myositis (sIBM) [1]. These groups are defined based

\footnotetext{
*Correspondence to: Olivier Benveniste, Assistance Publique Hôpitaux de Paris, Pitié-Salpêtrière University Hospital, Department of Internal Medicine and Clinical Immunology (DHU i2B), 47-83, boulevard de l'Hôpital, 75651 Paris cedex 13, France. Tel.: +33 142161088; Fax: +33 142161058, E-mail: olivier.benveniste@psl.aphp.fr.
}

on clinical presentation and muscle pathology. Nevertheless, important variations concerning phenotype (either muscular and/or extra-muscular), response to treatment and prognosis are observed within a given group.

In 1976, Reichlin and Mattioli [2] described the first myositis specific auto-antibody (MSA) identified in a patient with Mi initials, thus referring to it as antiMi-2. Later, anti-Mi-2 appears to be closely linked to $\mathrm{DM}$, and was the first specific serologic marker for this form of myositis [3]. Today, this MSA is known to be directed against the chromatin-remodelling Mi-2/NuRD complex and is found in $10-30 \%$ of 
Table 1

Myositis specific antibodies

\begin{tabular}{|c|c|c|c|c|c|c|}
\hline $\begin{array}{l}\text { Name of } \\
\text { the antibody }\end{array}$ & $\begin{array}{l}\text { Target of } \\
\text { the antibody }\end{array}$ & $\begin{array}{l}\text { Frequency } \\
\text { among auto- } \\
\text { immune } \\
\text { myopathies }\end{array}$ & $\begin{array}{l}\text { Acute } \\
\text { and severe } \\
\text { proximal } \\
\text { weakness }\end{array}$ & $\begin{array}{l}\text { Muscle } \\
\text { pathology }\end{array}$ & $\begin{array}{l}\text { Skin } \\
\text { lesions }\end{array}$ & $\begin{array}{l}\text { Life- } \\
\text { threatening } \\
\text { complication }\end{array}$ \\
\hline Anti-Jo-1 & Histidyl-t-RNA-synthetase & $15-20 \%$ & $+++/++$ & IMPP/NM & MH & ILD+/cardiac+ \\
\hline Anti-PL-7 & Threonyl-t-RNA-synthetase & $5 \%$ & $++/+$ & IMPP/NM & MH & ILD++ \\
\hline Anti-PL-12 & Alanine-t-RNA-synthetase & $<5 \%$ & $+/ \pm$ & IMPP/NM & MH & ILD++ \\
\hline Anti-OJ & Isoleucyl-t-RNA-synthetase & $<5 \%$ & $+/ \pm$ & not characterised & MH & ILD++ \\
\hline Anti-EJ & Glycyl-t-RNA-synthetase & $<5 \%$ & $+/ \pm$ & not characterised & $\mathrm{MH}$ & ILD++ \\
\hline Anti-Zo & Phenylalanyl-RNA-synthetase & $<5 \%$ & $+/ \pm$ & not characterised & MH & ILD++ \\
\hline Anti-Ha & anti-tyrosyl-RNA-synthetase & $<5 \%$ & $+/ \pm$ & not characterised & $\mathrm{MH}$ & ILD++ \\
\hline Anti-KS & Asparaginyl-t-RNA-synthetase & $<5 \%$ & $+/ \pm$ & not characterised & MH & ILD+ \\
\hline Anti-MI-2 & $\begin{array}{l}\text { Nuclesome remodeling- } \\
\text { deacetylase }\end{array}$ & $6 \%$ & ++ & IMPP & DM rash & none \\
\hline Anti-TIFl $\gamma$ & $\begin{array}{l}\text { Transcriptional intermediary } \\
\text { factor } 1 \gamma\end{array}$ & $6 \%$ & ++ & IMPP & DM rash & cancer \\
\hline Anti-MDA5 & $\begin{array}{l}\text { Melanoma differentiation } \\
\text { associated gene } 5\end{array}$ & $6 \%$ & \pm & not characterised & $\begin{array}{l}\text { DM rash, ulcers, } \\
\text { MH, palmar papules }\end{array}$ & ILD+++ \\
\hline Anti-SAE & $\begin{array}{l}\text { Small ubiquitin-like } \\
\text { modifier activating enzyme }\end{array}$ & $<5 \%$ & + & not characterised & DM rash & none \\
\hline Anti-NXP2 & Nuclear matrix protein 2 & $<5 \%$ & ++ & not characterised & $\begin{array}{l}\text { DM rash, } \\
\text { calcinosis }\end{array}$ & cancer \\
\hline Anti-SRP & Signal recognition particle & $5 \%$ & $+++/ \pm$ & NM & none & cardiac++ \\
\hline Anti-HMGCR & $\begin{array}{l}\text { 3-hydroxy-3-methylglu } \\
\text { tarylcoenzyme A } \\
\text { reductase }\end{array}$ & $6 \%$ & $+++/ \pm$ & NM & none & none \\
\hline Anti-cN1A & Cytosolic $5^{\prime}$-nucleotidase $1 \mathrm{~A}$ & $10 \%$ & - & sIBM & none & none \\
\hline
\end{tabular}

IMPP: immune myopathies with perimysial pathology was described by Pestronk and Mozaffar in patients with anti-synthetase syndrome and dermatomyositis [90]. NM: Necrotizing myopathy. DM rash: dermatomyositis rash. MH: mechanic's hand. ILD: interstitial lung disease.

patients with DM [4]. DM patients typically have more severe cutaneous manifestations but also experience a better response to steroid therapy and a diminished incidence of malignancy [5-7].

In 1980, Nishikai and Reichlin [8] described the second MSA identified in a patient with initials Jo, thus referencing it as anti-Jo-1. This MSA was observed in $30 \%$ of PM and $4 \%$ of DM patients. Three years later, the target of this antibody was discovered: antiJo-1 directed against (and functionally blocking) the histidyl tRNA-synthetase [9]. Aside from anti-histidyl tRNA-synthetase being described of which anti-Jo-1 was first among IIM, seven other anti-aminoacyl tRNA synthetase have been described (Table 1). Today, using different commercial immunoassays, we are able to detect anti-histidyl (Jo-1 also called PL-1), threonyl (PL-7), alanine (PL-12), isoleucyl (OJ) and glycyl (EJ) tRNA synthetase antibodies (Fig. 1). The first series of cases $(n=29)$ of anti-aminoacyl tRNA synthetase antibody positive patients was published in 1990, delineating a relatively homogeneous phenotype: the anti-synthetase syndrome which associates myositis, interstitial pneumonia, Raynaud's phenomenon, mechanic's hands and arthritis [10].
Love et al. in 1991 were the first to propose the use of MSA to classify IIM, followed by Troyanov et al. in 2005, who proposed the same approach in their serological classification [5, 11]. Of note, in this last classification the authors proposed that the term for PM should be used only for PM without MSA and/or myositis associated auto-antibodies (MAA), otherwise overlap myositis should be diagnosed [11], as most patients with these antibodies are presenting extra-muscular symptoms common with connective-tissue disorders. In parallel, PM begun to be viewed as an over diagnosed entity [12] and even as a mythological beast [13] (Fig. 1). However, several reviews highlight the usefulness of MSA in IIM $[14,15]$.

To date, over fifteen MSA as well as MAA have been characterised (Fig. 1 and Tables 1 and 2). Many can be detected through routine tests via multiple commercial line blot assays (figured in bold on Fig. 1). MSA are "only" observed in acquired myopathies, whereas MAA can also be detected in other auto-immune diseases, particularly connective-tissue disorders such as scleroderma. These MSA are usually mutually exclusive, i.e. in the vast majority of the cases when a 


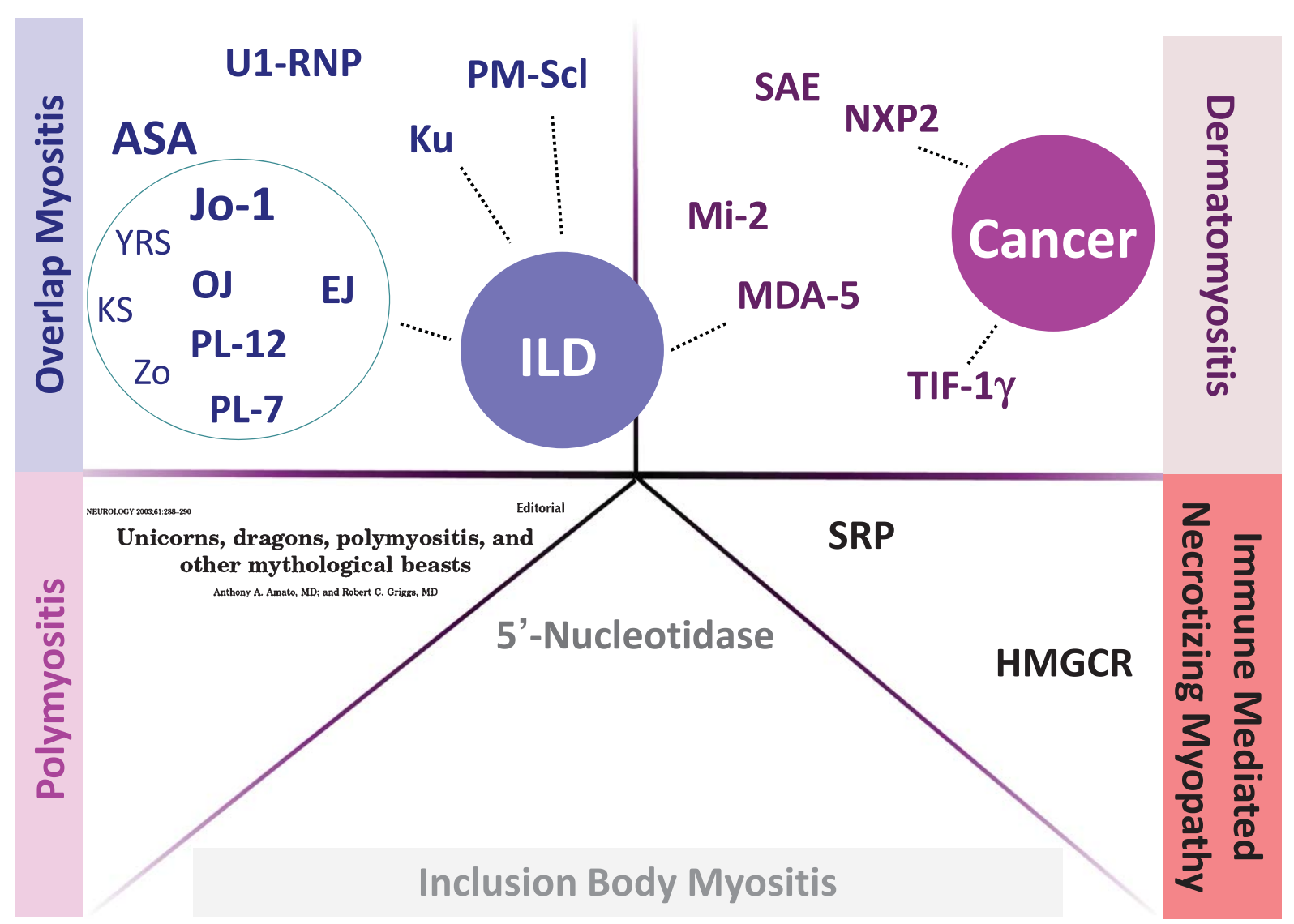

Fig. 1. Main myositis specific auto-antibodies (MSA) and myositis associated auto-antibodies (MAA) observed in the different subgroups of idiopathic inflammatory myopathies. N.B. Bold highlights antibodies, which today are routinely available, by commercial line dot assays. Dot lines show association between extra-muscular manifestation and the antibodies. ASA: anti-synthetase antibodies. ILD: interstitial lung disease.

Table 2

Myositis associated antibodies

\begin{tabular}{|c|c|c|c|c|c|}
\hline $\begin{array}{l}\text { Name of } \\
\text { the antibody }\end{array}$ & $\begin{array}{l}\text { Target of } \\
\text { the antibody }\end{array}$ & $\begin{array}{c}\text { Frequency } \\
\text { among auto- } \\
\text { immune myopathies }\end{array}$ & $\begin{array}{l}\text { Muscle } \\
\text { Pathology }\end{array}$ & $\begin{array}{l}\text { Life- } \\
\text { threatening } \\
\text { complication }\end{array}$ & $\begin{array}{l}\text { Associated } \\
\text { auto-immune } \\
\text { diseases }\end{array}$ \\
\hline Anti-Ro52 & TRIM21 & $30 \%$ & IMPP/PM & ILD & SSc, SS, SLE \\
\hline Anti-Ro-60/SSA & 60-kDa Ro & $10 \%$ & IMPP/PM & ILD & SSc, SS, SLE, RA \\
\hline Anti-La/SSB & $\mathrm{La}$ & $15 \%$ & IMPP/PM & ILD & SSc, SS, SLE, RA \\
\hline Anti-Ku & $\mathrm{Ku}$ & $20 \%$ & $\mathrm{PM}$ & ILD & $\mathrm{SSc}, \mathrm{SS}, \mathrm{SLE}$ \\
\hline Anti-URNP & Ribonucleoprotein & $15 \%$ & PM & none & Sharp syndrome \\
\hline Anti-Mitochondrial & Pyruvate deshydrogenase-E2 & $10 \%$ & $\begin{array}{l}\text { granulomatous } \\
\text { PM }\end{array}$ & cardiac & $\mathrm{PBC}$ \\
\hline Anti-PM/Scl & $\begin{array}{l}\text { nucleolar PM/Scl } \\
\text { macromolecular complex }\end{array}$ & $10 \%$ & $\mathrm{PM} / \mathrm{NM}$ & ILD, cardiac & SSc, SLE \\
\hline anti-CENP & Centromer & $<5 \%$ & $\mathrm{PM} / \mathrm{NM}$ & ILD, cardiac & $\mathrm{SSc}$ \\
\hline anti-topo & Topo-isomerases & $<5 \%$ & $\mathrm{PM} / \mathrm{NM}$ & ILD, cardiac & $\mathrm{SSc}$ \\
\hline anti-RNAPOLIII & RNA polymerase III & $<5 \%$ & $\mathrm{PM} / \mathrm{NM}$ & ILD, cardiac & $\mathrm{SSc}$ \\
\hline anti-fibrillarin & Fibrillarin & $15 \%$ & $\mathrm{PM} / \mathrm{NM}$ & ILD, cardiac & $\mathrm{SSc}$ \\
\hline anti-CCP & cyclic citrullinated peptide & $10 \%$ & IMPP/PM & ILD & RA \\
\hline Rheumatoid Factor & $\operatorname{IgG}$ & $20 \%$ & IMPP/PM & ILD & SSc, SS, SLE, RA \\
\hline
\end{tabular}

The reported frequency of antibodies are mainly derived from Koenig et al. [60] and Labrador-Horrillo et al. [91]. IMPP: immune myopathies with perimysial pathology [90]. NM: Necrotizing myopathy. DM rash: dermatomyositis rash. ILD: interstitial lung disease. PM: Polymyositis. SSc: Systemic sclerosis. SS: Sjögren syndrome, SLE: systemic lupus erythematosus. PBC: primary biliary cirrhosis. RA: Rheumatoid arthritis. 
patient presents with IIM, only one of those MSA are detected [16]. MSA and/or MAA are present in $80 \%$ of patients suffering from IIM [17], and 20-50\% of patients are positive for MSA [17-21], however, these studies have not used the last generation of immunodetection assays. As we will see below, the presence of MSA/MAA is associated with homogeneous muscular and extra-muscular phenotypes and prognosis. Indeed, detection of cancer and life-threatening complications, therapeutic choices and follow-up as well must be carried out according to the presence of MSA/MAA, which becomes paramount in the management of IIM.

In this review focusing on the diagnostic utility of MSA and MAA, we will see i) which auto-antibody may be observed depending on the muscular and the extra-muscular phenotype, ii) how MSA and MAA are useful to differentiate IIM from other genetic or acquired myopathies, and iii) how MSA permits precise prognosis, cancer association and therapeutic options.

\section{PHENOTYPES AND AUTO-ANTIBODIES}

Depending on type of the clinical presentation including both muscular and extra-muscular phenotypes presence of MSA and/or MAA may be suggested.

\section{Muscular manifestations}

\section{Clinical phenotype}

The common clinical characteristic of IIM is the presence of muscle weakness. There are indeed great variations in weakness between the different groups of IIM (and even within a group) ranging from a very severe muscle deficit with an acute onset to the absence of muscle deficit (so called "amyopathic" IIM).

An acute or sub-acute onset (in less than 3 months) of severe (Medical Research Council grade $\leq 3 / 5$ ) proximal weakness with myalgia is frequently observed in IMNM associated with anti-signal recognition protein (SRP) or anti-hydroxymethylglutaryl-coenzyme A reductase (HMGCR) antibody [22-24]. Similarly, these MSA are also associated with high creatine kinase (CK) levels (>5,000 I.U/L) compared to other IIM [24-26]. Patients with anti-SRP or anti-HMGCR antibodies may also frequently (20-30\%) suffer from dysphagia [24, 25], again more common than in other IIM [25].

Anti-Jo-1 positive patients may also present with severe weakness associated with myalgia and high CK level [27], but in general the severity of muscle deficit is not worse than any other IIM $[5,28]$. As we have seen previously, anti-Jo-1 antibodies target the histidyl-tRNA synthetase and, to date, there are seven other MSA recognising different aminoacyl-tRNA synthetases (Table 1). After anti-Jo-1, anti-threonyl (anti-PL-7) and anti-alanyl (anti-PL-12) are most frequently detected [17, 21]. However, there are slight differences in phenotype depending on which aminoacyl-tRNA synthetases are targeted. Indeed, compared to patients with antiJo-1, anti-PL7 and anti-PL12 patients have a less severe myositis with more severe interstitial lung disease $[16,29]$. Conversely, the very rare patients with antiasparaginyl tRNA synthetase (anti-KS) antibodies do not have clinical evidence of myositis [30]. Similarly, the anti-CADM-140 antibody (31), is associated with amyopathic DM (clinically amyopathic DM: CADM [32]). Once its molecular target was identified, this MSA was renamed anti-Melanoma differentiated gene 5 (MDA5) antibody [33]. Nevertheless, DM patients positive for anti-MDA5 antibody may also present signs of myositis even if their muscle weakness and/or increase of CK levels are milder compared with "classical" DM [34].

Slowly progressive muscular deficit with a proximal, distal and asymmetric topography is one of the hallmarks of sIBM, notably the selective weakness of finger flexion and knee extension [35]. Recently, sIBM-specific auto-antibodies have been alluded to and described. An antibody recognizing a $43 \mathrm{kD}$ antigenic target was found in the serum of 13 out of 25 sIBM patients but not in 40 controls (healthy subjects or patients with other inflammatory myopathies) [36]. The antigenic target of this sIBM associated auto-antibodies has been identified by two independent groups as cytosolic $5^{\prime}$-nucleotidase $1 \mathrm{~A}$ (anti-cN1A) $[37,38]$; an enzyme involved in nucleotide metabolism which is expressed at a relatively high level in skeletal muscle. Anti-cN1A autoantibodies were present in one third of sIBM patients $[37,38]$, as compared to $\leq 5 \%$ in PM and DM [37, 38]. Nonetheless, the specificity to sIBM of this newly described anti-cN1A autoantibody has not yet been fully evaluated and further studies are required, particularly in other groups of connective tissue diseases such as rheumatoid arthritis, lupus or systemic sclerosis. If sIBM diagnosis is based on clinical and pathological criteria [39] then in some cases the diagnosis remains uncertain; therefore the presence of this MSA could be helpful to consolidate the diagnosis. Similarly, the presence of MSA or MAA (anti$\mathrm{cN} 1 \mathrm{~A}$ or anti-PM/Scl antibody) could be helpful in the diagnosis of IIM (e.g. sIBM, scleromyositis) [40] as 

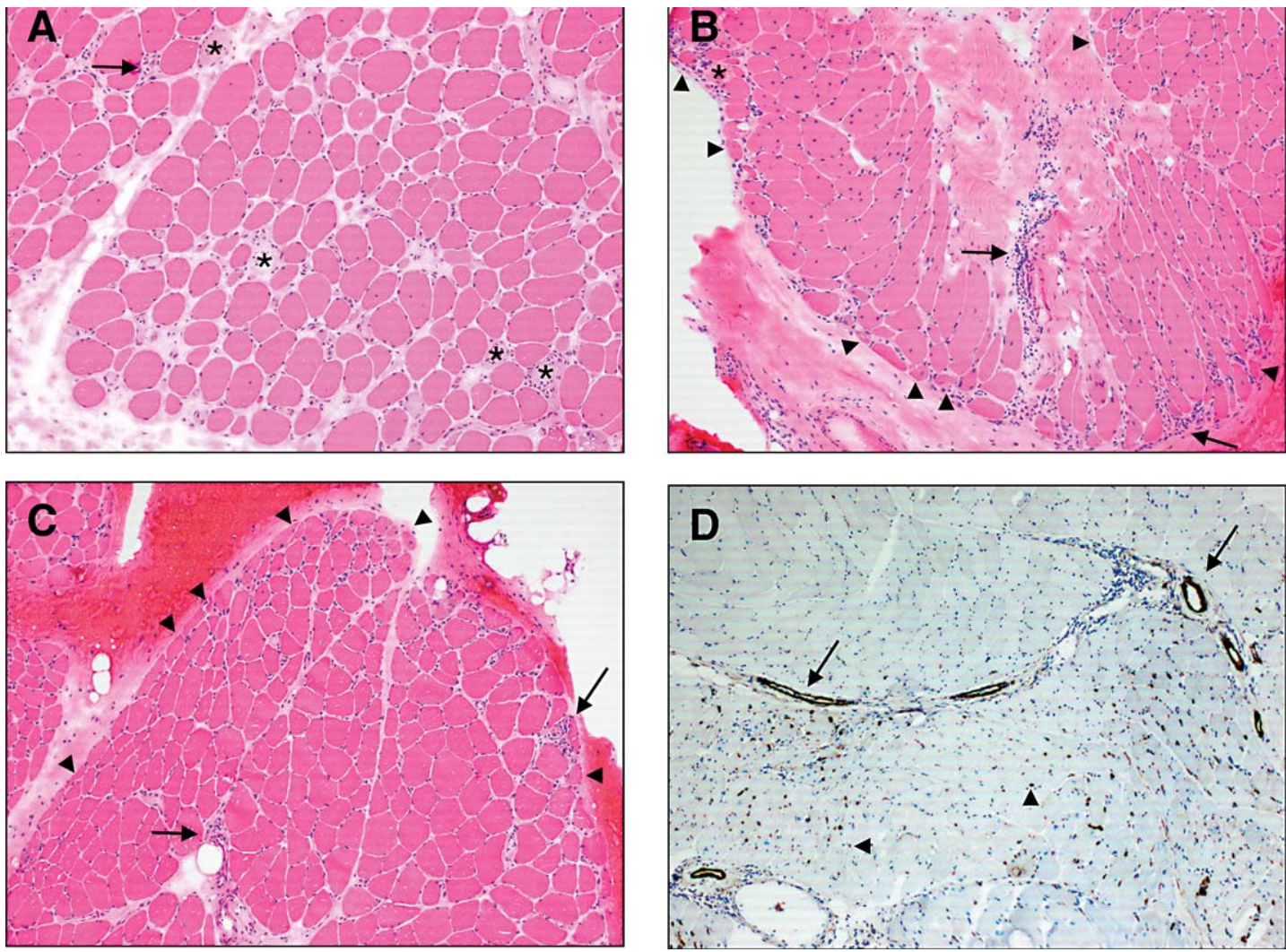

Fig. 2. Histological features of muscle based on the presence of myositis specific auto-antibodies (MSA). (A) Muscle fibre necrosis (asterisk) with minimal inflammatory infiltrates involved in phagocytosis of necrotic fibres (arrow) in a patient with anti-SRP antibody. (B) In patients with anti-synthetase syndrome, muscle fibre injuries occur mainly in perifascicular areas with fibre atrophy (arrow head), and/or necrosis (asterisk). Inflammatory infiltrates are present in perimysial and perifascicular regions (arrow). (C) Muscle fibre atrophy (arrow head) in perifascicular regions and the presence of inflammatory infiltrates in a perivascular and perimysial regions (arrows) are also observed in DM patients. (D) Vasculopathy with important C5b-9 depositions within capillaries in a DM patient (arrow head). Of note physiological positive C5b-9 staining on small arteries (arrows).

unusual muscle deficit, such as dropped head, maybe observed.

Beside the classical skeletal muscular manifestation, cardiac involvement is rare but may expose IIM patients to threatening complications. The MSA antiSRP antibody is associated with a risk of cardiac complication [41] and several reports have also shown cardiac involvement in anti-synthetase syndrome [42]. Two MAA have further been reported with increased risk of cardiac involvement: anti-mitochondrial and anti-PM/Scl antibodies [43, 44].

\section{Pathological features}

Most muscle biopsies from Anti-SRP and antiHMGCR patients show features of IMNM including predominant muscle necrosis and little or no inflammation (Fig. 2A), even if a minority of patients may have significant muscular infiltrates [22, 24, 26]. Some patients with anti-Jo-1 antibody may also have patho- logical features of IMNM [45], but the majority of these patients have a myositis with significant inflammation on muscle biopsy [14]. This pathological feature of anti-Jo-1 patients is characteristic. Myopathological changes occur in perifascicular regions with the presence of fibre atrophy, with inflammation mainly observed in perimysial regions [14] (Fig. 2B). These features are close to those observed in DM patients [14] leading to classification of patients with anti-synthetase syndrome in the DM group [34, 46] (Fig. 2C and D). However, pathological features in patients with anti-Jo-1 appears different since Mozzafar and Pestronk only observed a vasculopathy in DM [14]. The pathological changes currently observed in DM patients (perifascicular atrophy, perimysial inflamation near vascular regions and vasculopathy) are present in patients positive for MSA associated with DM [1] (Table 1, Fig. 2C and D). Patients with anti-mitochondrial antibodies 
may present also a specific pattern with muscle inflammation with the presence of granulomatous lesions [43], yet none of these patients would be considered as suffering from sarcoidosis.

\section{Extra-muscular manifestation}

Patients with anti-HMGCR antibody do not present with extra-muscular manifestations, and a minority of patients with anti-SRP antibody have discrete interstitial lung disease [24-26]. Conversely patients with other MSA and/or MAA frequently have extramuscular manifestation and notably life threatening interstitial lung disease which may represent the beginning of disease.

\section{Lung disease}

Presence of interstitial lung disease (ILD) is one of the most frequent manifestations [70-90\%) in patients with anti-aminoacyl-tRNA synthetase antibody [5, 47]. The presence of ILD also predicts the prognosis of those with anti-synthetase syndrome [27, 48]. Patients with anti-PL7 and anti-PL12 have an increased severity of lung disease compared to anti-Jo-1 patients $[16,49]$. The CT scan aspect (which on rare occasions was confirmed by lung histology) is mainly non-specific interstitial pneumonia without (Fig. 3A) or with fibrosis (Fig. 3B) [50, 51]. Less frequently, usual interstitial pneumonitis (Fig. 3C), cryptogenic organizing pneumonia (Fig. 3D) are also described

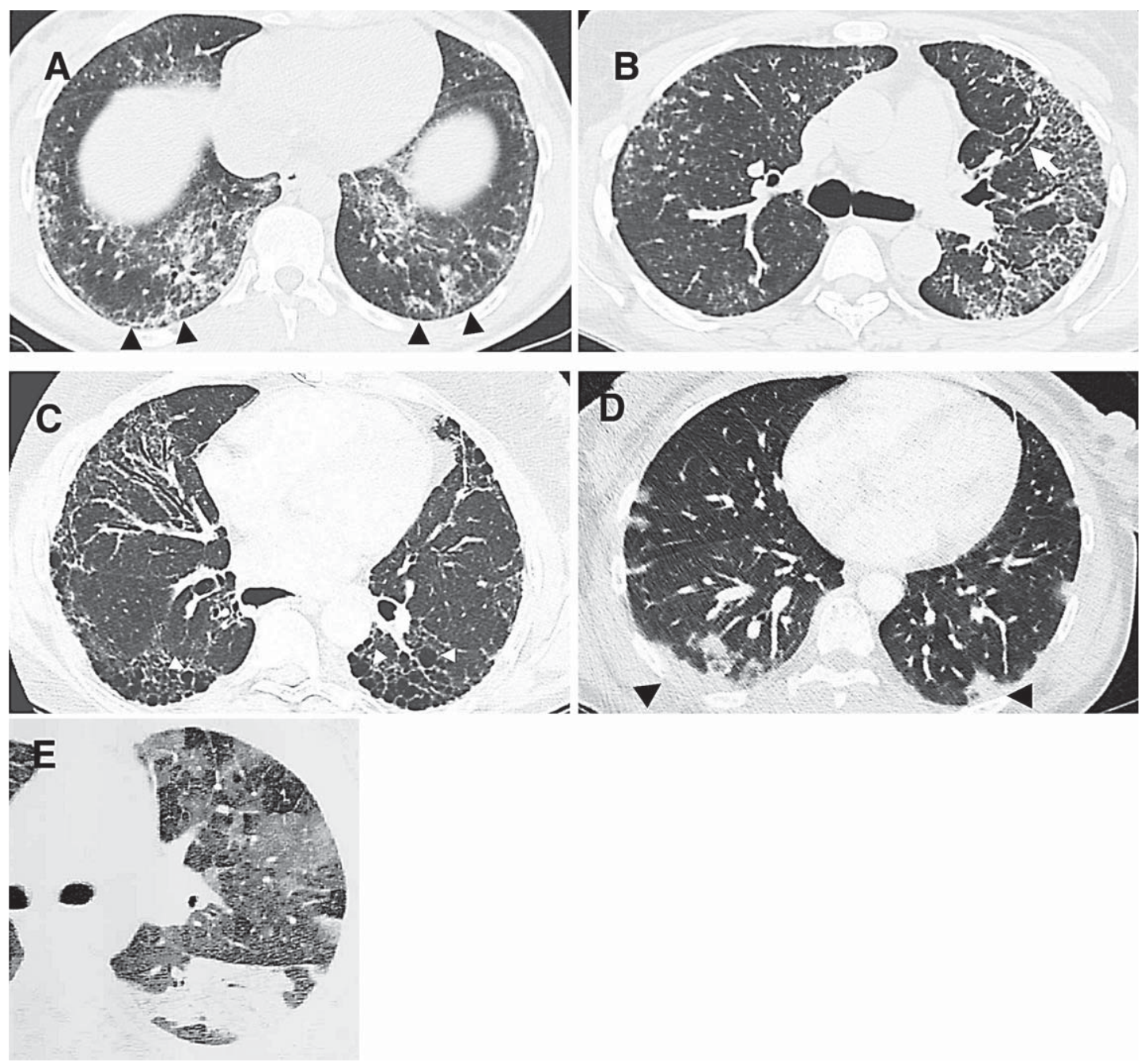

Fig. 3. Different patterns on CT scan of interstitial lung disease occurring during anti-synthetase syndrome. (A) Non-specific interstitial pneumonia with the presence of subpleural reticulations (black arrow heads). (B) Non-specific interstitial pneumonia with fibrosis characterised by the presence of traction bronchiectasis (white arrow). (C) Usual interstitial pneumonia with presence of honeycombing (white arrow heads). (D) Cryptogenic organising pneumonitis with presence of bilateral peripheral consolidations (black arrow heads). (E) Diffuse alveolar damage with presence of diffuse ground glass and consolidation opacities. 

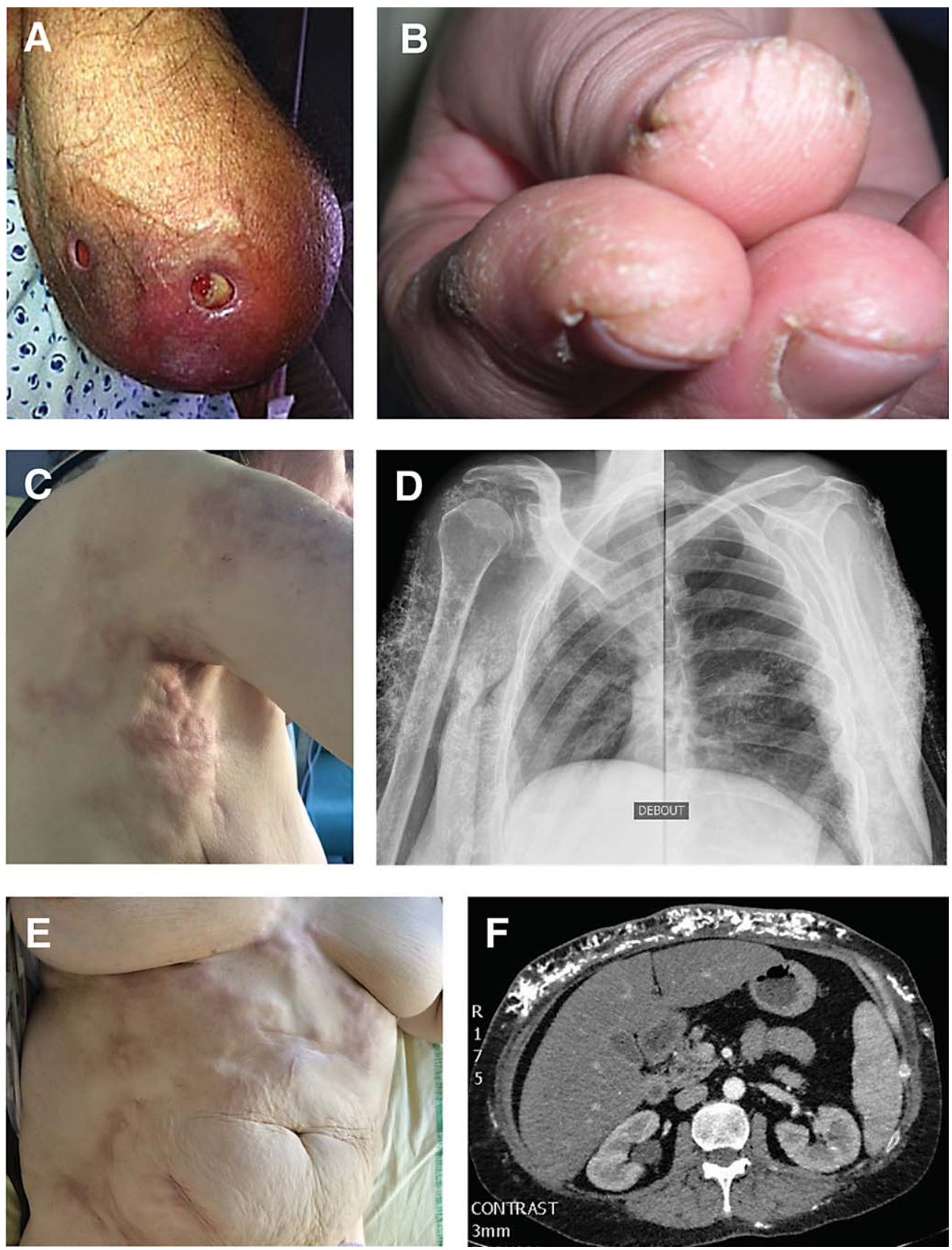

Fig. 4. Skin lesions. (A) Elbow skin ulcers in a DM patient with anti-MDA5 antibodies. (B) Mechanich's hand in a patient with anti-Jo-1 antibody. (C) Calcinosis cutis on the trunk and on the right arm of a DM patient with anti-NXP2 antibodies. (D) X-ray of both arms revealing the presence of calcifications. (E) Calcinosis cutis also present on the abdomen and (F) detectable by abdominal CT scan.

$[50,51]$. The most severe lesions with an immediate life-threatening prognosis are diffuse alveolar damage (Fig. 3E) [51]. The occurrence of pulmonary hypertension in anti-synthetase syndrome is significant (8\%), although presumably related to interstitial lung disease, it dramatically worsens the prognosis [52].
Additionally patients with anti-MDA5 present almost always ( $>80 \%)$ with an ILD and the anti-MDA5 antibody is the only DM MSA specifically associated with lung disease [34]. The rapidity of progression of that ILD in patients with anti-MDA5 antibody is also remarkable leading to an acute respiratory 
failure much more frequently than in patients with anti-synthetase antibodies [34, 48, 51]. Anti-Ro52 antibody is the most common MAA frequently associated with anti-synthetase antibodies [17]. Patients who are anti-Jo-1 antibody positive seem to often have a greater severity of ILD in the presence of anti-Ro52 [53, 54]. Anti-PM/Scl and anti-Ku antibodies positive patients present frequently with an associated ILD [44, 55].

\section{Skin lesions}

Typical DM skin rash is by definition observed in DM patients with or without MSA [1], nevertheless, atypical skin lesions are also documented in DM depending on which MSA is present. Anti-MDA5 antibody positive DM patients present more frequently with skin ulcerations (Fig. 4A), palmar papules and mechanics' hands [56]. DM patients with anti- nuclear matrix protein NXP-2 (NXP-2) antibody have higher occurrences of calcinosis (Fig. 4 C-F), especially in juvenile DM [57, 58]. Patients with anti-synthetase syndrome present frequently with "mechanics' hands" (Fig. 4B), and characteristically, patients with antiPL7 or anti-PL12 antibodies have sclerodactyly leading occasionally to a systemic sclerosis diagnosis since they also have Raynaud phenomenon and interstitial lung disease [46]. Anti-Ku and anti-PM/Scl antibody positive patients may also have sclerodactyly whether or not they present systemic sclerosis overlapping with their myositis [44, 55]. Similarly, patients with IIM associated with systemic lupus erythematosus, systemic sclerosis and related MAA, have skin manifestations linked to the underlying connective tissue disorder [59].

\section{Other extra-muscular manifestations}

Arthralgia (and less frequently arthritis) is frequently observed in patients with anti-synthetase syndrome and in patients with anti-MDA5 antibody [27, 34]. Pyrexia and/or weight loss are observed mainly in-synthetase syndrome, anti-MDA5, anti-SRP and anti-HMGCR antibody positive patients [24, 25, 27, 34, 47]. Of note, systemic manifestations related to connective tissue diseases are present in overlapping myositis with MAA (e.g. systemic erythematosus lupus, rheumatoid arthritis systemic sclerosis, or sharp syndrome) [59, 60]. Also, one third of patients with anti-mitochondrial antibodies present with a primary biliary cirrhosis [43].

\section{AUTO-ANTIBODIES AND DIFFERENTIAL DIAGNOSIS}

In patients suffering from myopathies, the presence of MSA or MAA is an argument for auto-immune mechanisms. Especially the presence of MSA which may be crucial to differentiate a muscular dystrophy from an acquired myopathy. Some patients with anti-SRP and/or anti-HMGCR have a slowly progressive muscle weakness, and muscle biopsies, performed after long disease duration, show muscle necrosis, irregular size of fibres and endomysial fibrosis. Together, these features may lead to the diagnosis of a muscular dystrophy whereas no muscular protein deficiency or mutation have been detected [24, 61]. In those cases detection of MSA is crucial because based on these results, patients should receive efficacious treatments (immunosuppressants).

Similarly, as discussed in the first section, unusual muscular deficits (e.g: dropped head) occurring during true IIM may be diagnosed with the help of MAA or MSA.

Besides IMNM, necrotizing myopathies can also be due to toxins or drugs, including statins. Usually toxic myopathies improve rapidly after withdrawal of their causal agent. Nevertheless, it has been reported that increased CK levels and/or muscular symptoms may persist over months after statin withdrawal, suggesting that toxic myopathy may persist for a longer time than expected [62]. In parallel, Mammen et al. described the existence of IMNM with anti-HMGCR antibodies occurring in patients exposed to statins [26]. Of note, this MSA was not detected in a large cohort of statin-exposed patients including those with selflimited statin intolerance [63]. The induction of IMNM with anti-HMGCR antibodies therefore seems a rare event in patients exposed to statins [24]. Thus, antiHMGCR may be advantageous in differentiating statin intolerance from cases of IMNM induced by statins.

Since patients with anti-MDA5 antibodies or anti-synthetase syndrome may present significant interstitial lung disease and/or arthritis with few or no sign of myositis, these MSA are also useful to pulmonologists/rheumatologists/dermatologists for distinctions with other conditions.

\section{PROGNOSIS, CANCER ASSOCIATION AND TREATMENT}

\section{Prognosis}

Cardiac involvement, interstitial lung disease and cancer are three major causes of mortality in patients with IIM [64-67]. We showed previously how certain MSA and/or MAA are strongly associated with cardiac (e.g., anti-SRP, anti-mitochondrial antibodies) and/or lung diseases (anti-synthetases, anti-MDA5, but 
also anti-Ku [68] and anti-PM ScL antibodies [44] see Tables 1 and 2). Therefore these antibodies could delineate subgroups of patients, where thorough screening and follow-up should be performed.

\section{Cancer association}

Auto-immune myositis (mainly in DM patients) is associated with cancer in approximately $20-30 \%$ of the cases [69]. Two MSA are also strongly associated with cancer and become useful tools to delineate patients in whom an intense screening must be performed.

The first described was discovered in 2006 by Targoff et al. as a newly recognised auto-antibody with a $155 / 140 \mathrm{kDa}$ protein in DM patients and particularly in cancer-associated DM [70]. The target of this anti$155 / 140$ antibody was concomitantly published by the same group as the anti-transcription intermediary factor $1 \gamma($ TIF1- $\gamma)$. Anti-TIF1- $\gamma$ and cancer-associated DM were repeatedly found associated in different studies (for review see [71]). Finally, this MSA had a positive predictive value of $58 \%$ and a negative predictive value of $95 \%$ for cancer association in DM [71]. Similarly, it was recently shown that anti-NXP-2 antibody, a MSA observed in DM patients, was specifically associated with cancer [72, 73]. Conversely, to date, other MSA specific for DM (Table 1) and in particular the oldest described ones anti-Mi-2, are not associated with cancer [34]. Also, patients with antisynthetase syndrome do not have an increased risk of cancer [47]. If there are data reporting associations between necrotizing myopathy and cancer, to date there is no increased frequency of cancer in anti-SRP or anti-HMGCR antibodies positive IMNM [24, 25].

\section{Treatment}

Two-third of patients with anti-synthetase antibodies need disease-modifying anti-rheumatic drugs (in other words: immunosuppressant intensification) [27] and patients with IMNM with MSA (Anti-SRP or anti-HMGCR $\mathrm{Ab}$ ) are characterised by a long disease duration with numerous relapses [24, 25]. These observations led to considering the association of both corticosteroid and an immunosuppressant (which can be methotrexate or azathioprine, at least, for their corticosteroid sparing effects) as initial treatment for these patients [11]. Also, because of life-threatening complications of ILD, combined treatment need to be discussed in IIM patients with MSA and/or MAA and lung involvement. In severe lung disease (as frequently encountered in anti-MDA5 or anti-synthetases antibody positive patients) cyclophosphamide, cyclosporine or tacrolimus are drugs which have shown positive results [74-77]. Rituximab seems also to be sometimes efficacious in this situation [78].

Since levels of anti-Jo-1, anti-MDA5, anti-SRP and anti-HMGCR antibody are correlated with the activity of the disease [24, 79-82], MSA could be involved in the pathogenesis of these IIM. Therefore, treatments targeting antibody production and/or pathways activated by immune complexes could be efficacious in patients with MSA. To this aim, B cell depleting immunotherapy may be an option. Indeed, rituximab may be efficacious in refractory IIM [83] and presence of anti-MI-2 or anti-synthetase syndrome predict clinical improvement [84]. Removing antibodies (plasma exchanges) in the acute phase of auto-immune myopathy with MSA also showed positive results $[85,86]$. The immuno-modulator treatment: intra-venous immunoglobulins (IVIg) could modulate effects of pathogenic antibody by inhibiting activation of complement and/or fixation to their cognate antigens (anti-idiotypic effect) [87]. Several studies have shown that IVIg can have a beneficial effect on DM and PM, particularly when associated to MSA [88]. Nevertheless, further studies designed for patients with MSA are needed to document the place of immunosuppressants, biotherapies and IVIg. Eculizumab is a monoclonal antibody directed against the complement protein C5 (complement inhibitor), could theoretically be interesting in IIM involving complement activation and MSA but studies are needed to confirm its utility [89].

\section{CONCLUSIONS}

MAA and MSA are very relevant diagnostic tools for diagnosis and classification of IIM. To date, different immunoassays permit detection, at a modest cost, many of the MSA/MAA (Fig. 1). The presence of MAA and/or MSA strongly suggests auto-immune mechanisms in patients suffering from muscular symptoms. MSA or MAA delineate subgroups of IIM patients with consistent clinical phenotype (muscular and extra-muscular manifestations, notably ILD and cancer (Fig. 1)), common prognostic (mortality and disease duration) and treatment responses. They also permit to identify homogeneous groups of patients more precisely than the classical international classification of myositis did (based on clinic and pathology) [1], leading to consider MSA and/or MAA as relevant diagnostic criteria in further 
classification. Nevertheless, the exact proportion of patients with MSA and or MAA remains unknown and further studies with an exhaustive screening are needed. In addition, since clinical trials have been performed with patients PM and/or DM, further studies enrolling homogenous groups of patients based on presence of MSA and with specific outcome measures adapted to these phenotypes are needed to determine specific therapeutic strategies in those patients.

\section{ACKNOWLEDGMENTS}

We thanks Dr Hervier, Dr Leroux and Dr Rigolet for their precious help for building the figures.

\section{CONFLICTS OF INTEREST}

Y. Allenbach and O. Benveniste have no conflict of interest to declare concerning this review.

\section{REFERENCES}

[1] Hoogendijk, J. E., Amato, A. A., Lecky, B. R., Choy, E. H., Lundberg, I. E., Rose, M. R., et al. 119th ENMC international workshop: Trial design in adult idiopathic inflammatory myopathies, with the exception of inclusion body myositis, 10-12 October 2003, Naarden, The Netherlands. Neuromuscul Disord. 2004; 14(5): 337-345.

[2] Reichlin, M., Mattioli, M. Description of a serological reaction characteristic of polymyositis. Clin Immunol Immunopathol. 1976; 5(1): 12-20.

[3] Targoff, I. N., Reichlin, M. The association between Mi-2 antibodies and dermatomyositis. Arthritis Rheum. 1985; 28(7): 796-803.

[4] Ghirardello, A., Zampieri, S., Iaccarino, L., Tarricone, E., Bendo, R., Gambari, P. F., et al. Anti-Mi-2 antibodies. Autoimmunity. 2005; 38(1): 79-83.

[5] Love, L. A., Leff, R. L., Fraser, D. D., Targoff, I. N., Dalakas, M., Plotz, P. H., et al. A new approach to the classification of idiopathic inflammatory myopathy: Myositis-specific autoantibodies define useful homogeneous patient groups. Med Baltim. 1991; 70(6): 360-374.

[6] Targoff, I. N. Laboratory testing in the diagnosis and management of idiopathic inflammatory myopathies. Rheum Clin North Am. 2002; 28(4): 859-890, viii.

[7] Hengstman, G. J. D., Egberts, W. T. M. V., Seelig, H. P., Lundberg, I. E., Moutsopoulos, H. M., Doria, A., et al. Clinical characteristics of patients with myositis and autoantibodies to different fragments of the Mi-2? antigen. Ann Rheum Dis. 2006; 65(2): 242-245.

[8] Nishikai, M., Reichlin, M. Heterogeneity of precipitating antibodies in polymyositis and dermatomyositis. Characterization of the Jo-1 antibody system. Arthritis Rheum. 1980; 23(8): 881-888.

[9] Mathews, M. B., Bernstein, R. M. Myositis autoantibody inhibits histidyl-tRNA synthetase: A model for autoimmunity. Nature. 1983; 304(5922): 177-179.

[10] Marguerie, C., Bunn, C. C., Beynon, H. L., Bernstein, R. M., Hughes, J. M., So, A. K., et al. Polymyositis, pulmonary fibrosis and autoantibodies to aminoacyl-tRNA synthetase enzymes. Q J Med. 1990; 77(282): 1019-1038.

[11] Troyanov, Y., Targoff, I. N., Tremblay, J. L., Goulet, J. R., Raymond, Y., Senecal, J. L. Novel classification of idiopathic inflammatory myopathies based on overlap syndrome features and autoantibodies: Analysis of 100 French Canadian patients. Med Baltim. 2005; 84(4): 231-249.

[12] Van der Meulen, M. F., Bronner, I. M., Hoogendijk, J. E., Burger, H., van Venrooij, W. J., Voskuyl, A. E., et al. Polymyositis: An overdiagnosed entity. Neurology. 2003; 61(3): 316-321.

[13] Amato, A. A., Griggs, R. C. Unicorns, dragons, polymyositis, and other mythological beasts. Neurology. 2003; 61(3): 288-289.

[14] Casciola-Rosen, L., Mammen, A. L. Myositis autoantibodies. Curr Opin Rheumatol. 2012; 24(6): 602-608.

[15] Sibilia, J., Chatelus, E., Meyer, A., Gottenberg, J.-E., Sordet, C., Goetz, J. How can we diagnose and better understand inflammatory myopathies? The usefulness of auto-antibodies. Presse Médicale Paris Fr 1983. 2010; 39(10): 1010-1025.

[16] Hervier, B., Devilliers, H., Stanciu, R., Meyer, A., Uzunhan, Y., Masseau, A., et al. Hierarchical cluster and survival analyses of antisynthetase syndrome: Phenotype and outcome are correlated with anti-tRNA synthetase antibody specificity. Autoimmun Rev. 2012; 12(2): 210-217.

[17] Koenig, M., Fritzler, M. J., Targoff, I. N., Troyanov, Y., Senécal, J.-L. Heterogeneity of autoantibodies in 100 patients with autoimmune myositis: Insights into clinical features and outcomes. Arthritis Res Ther. 2007; 9(4): R78.

[18] Cruellas, M. G. P., dos Santos Trindade Viana, V., LevyNeto, M., de Souza, F. H. C., Shinjo, S. K. Myositis-specific and myositis-associated autoantibody profiles and their clinical associations in a large series of patients with polymyositis and dermatomyositis. Clinics. 2013; 68(7): 909-914.

[19] Rönnelid, J., Barbasso Helmers, S., Storfors, H., Grip, K., Rönnblom, L., Franck-Larsson, K., et al. Use of a commercial line blot assay as a screening test for autoantibodies in inflammatory myopathies. Autoimmun Rev. 2009; 9(1): 58-61.

[20] Dobloug, C., Garen, T., Bitter, H., Stjärne, J., Stenseth, G., Grøvle, L., et al. Prevalence and clinical characteristics of adult polymyositis and dermatomyositis; data from a large and unselected Norwegian cohort. Ann Rheum Dis. 2014.

[21] Brouwer, R., Hengstman, G. J., Vree Egberts, W., Ehrfeld, H., Bozic, B., Ghirardello, A., et al. Autoantibody profiles in the sera of European patients with myositis. Ann Rheum Dis. 2001; 60(2): 116-123.

[22] Miller, T., Al-Lozi, M. T., Lopate, G., Pestronk, A. Myopathy with antibodies to the signal recognition particle: Clinical and pathological features. J Neurol Neurosurg Psychiatry. 2002; 73(4): 420-428.

[23] Mammen, A. L., Chung, T., Christopher-Stine, L., Rosen, P., Rosen, A., Doering, K. R., et al. Autoantibodies against 3-hydroxy-3-methylglutaryl-coenzyme A reductase in patients with statin-associated autoimmune myopathy. Arthritis Rheum. 63(3): 713-721.

[24] Allenbach, Y., Rigolet, A., Drouot, L., Charuel, J., Jouen, F. Maisonobe, T., et al. Auto-immune necrotizing myopathies with anti-HMGCR antibodies are related to statin-exposure only for a minority of cases. WMS Congr Asilomar Conf Grounds Calif USA. 2013.

[25] Hengstman, G. J. D., ter Laak, H. J., Vree Egberts, W. T. M., Lundberg, I. E., Moutsopoulos, H. M., Vencovsky, J., et al. Anti-signal recognition particle autoantibodies: Marker 
of a necrotising myopathy. Ann Rheum Dis. 2006; 65(12): 1635-1638.

[26] Mammen, A. L., Chung, T., Christopher-Stine, L., Rosen, P., Rosen, A., Doering, K. R., et al. Autoantibodies against 3-hydroxy-3-methylglutaryl-coenzyme A reductase in patients with statin-associated autoimmune myopathy. Arthritis Rheum. 2011; 63(3): 713-721.

[27] Stanciu, R., Guiguet, M., Musset, L., Touitou, D., Beigelman, C., Rigolet, A., et al. Antisynthetase syndrome with anti-Jo antibodies in 48 patients: Pulmonary involvement predicts disease-modifying antirheumatic drug use. J Rheumatol. 2012; 39(9): 1835-1839.

[28] Mielnik, P., Wiesik-Szewczyk, E., Olesinska, M., Chwalinska-Sadowska, H., Zabek, J. Clinical features and prognosis of patients with idiopathic inflammatory myopathies and anti-Jo-1 antibodies. Autoimmunity. 2006; 39(3): 243-247.

[29] Marie, I., Josse, S., Decaux, O., Dominique, S., Diot, E., Landron, C., et al. Comparison of long-term outcome between anti-Jo1- and anti-PL7/PL12 positive patients with antisynthetase syndrome. Autoimmun Rev. 2012; 11(10): 739-745.

[30] Hirakata, M., Suwa, A., Nagai, S., Kron, M. A., Trieu, E. P., Mimori, T., et al. Anti-KS: Identification of autoantibodies to asparaginyl-transfer RNA synthetase associated with interstitial lung disease. J Immunol Baltim Md 1950. 1999; 162(4): 2315-2320.

[31] Sato, S., Hirakata, M., Kuwana, M., Suwa, A., Inada, S. Mimori, T., et al. Autoantibodies to a $140-\mathrm{kd}$ polypeptide, CADM-140, in Japanese patients with clinically amyopathic dermatomyositis. Arthritis Rheum. 2005; 52(5): 1571-1576.

[32] Euwer, R. L., Sontheimer, R. D. Amyopathic dermatomyositis: A review. J Invest Dermatol. 1993; 100(1): 124S-127S.

[33] Sato, S., Hoshino, K., Satoh, T., Fujita, T., Kawakami, Y., Fujita, T., et al. RNA helicase encoded by melanoma differentiation-associated gene 5 is a major autoantigen in patients with clinically amyopathic dermatomyositis: Association with rapidly progressive interstitial lung disease. Arthritis Rheum. 2009; 60(7): 2193-2200.

[34] Hamaguchi, Y., Kuwana, M., Hoshino, K., Hasegawa, M., Kaji, K., Matsushita, T., et al. Clinical correlations with dermatomyositis-specific autoantibodies in adult Japanese patients with dermatomyositis: A multicenter cross-sectional study. Arch Dermatol. 2011; 147(4): 391-398.

[35] Benveniste, O., Guiguet, M., Freebody, J., Dubourg, O., Squier, W., Maisonobe, T., et al. Long-term observational study of sporadic inclusion body myositis. Brain. 2011; 134(Pt 11): 3176-3184

[36] Salajegheh, M., Lam, T., Greenberg, S. A. Autoantibodies against a $43 \mathrm{KDa}$ muscle protein in inclusion body myositis. PloS One. 2011; 6(5): e20266.

[37] Pluk, H., van Hoeve, B. J., van Dooren, S. H., StammenVogelzangs, J., van der Heijden, A., Schelhaas, H. J., et al. Autoantibodies to cytosolic $5^{\prime}$-nucleotidase $1 \mathrm{~A}$ in inclusion body myositis. Ann Neurol. 2013; 73(3): 397-407.

[38] Larman, H. B., Salajegheh, M., Nazareno, R., Lam, T., Sauld, J., Steen, H., et al. Cytosolic $5^{\prime}$-nucleotidase $1 \mathrm{~A}$ autoimmunity in sporadic inclusion body myositis. Ann Neurol. 2013; 73(3): 408-418.

[39] Griggs, R. C., Askanas, V., DiMauro, S., Engel, A., Karpati, G., Mendell, J. R., et al. Inclusion body myositis and myopathies. Ann Neurol. 1995; 38(5): 705-713.

[40] Garcin, B., Lenglet, T., Dubourg, O., Mesnage, V., Levy, R. Dropped head syndrome as a presenting sign of scleromyositis. J Neurol Sci. 2010; 292(1-2): 101-103.
[41] Kao, A. H., Lacomis, D., Lucas, M., Fertig, N., Oddis, C. V. Anti-signal recognition particle autoantibody in patients with and patients without idiopathic inflammatory myopathy. Arthritis Rheum. 2004; 50(1): 209-215.

[42] Sharma, K., Orbai, A. -M., Desai, D., Cingolani, O. H., Halushka, M. K., Christopher-Stine, L., et al. Brief report: Antisynthetase syndrome-associatedmyocarditis.JCardFail.2014.

[43] Maeda, M. H., Tsuji, S., Shimizu, J. Inflammatory myopathies associated with anti-mitochondrial antibodies. Brain. 2012; 135(Pt 6): 1767-1777.

[44] Ranque, B., Authier, F. J., Le-Guern, V., Pagnoux, C., Berezne, A., Allanore, Y., et al. A descriptive and prognostic study of systemic sclerosis-associated myopathies. Ann Rheum Dis. 2009; 68(9): 1474-1477.

[45] Christopher-Stine, L., Casciola-Rosen, L. A., Hong, G., Chung, T., Corse, A. M., Mammen, A. L. A novel autoantibody recognizing $200-\mathrm{kd}$ and $100-\mathrm{kd}$ proteins is associated with an immune-mediated necrotizing myopathy. Arthritis Rheum. 2010; 62(9): 2757-2766.

[46] Hamaguchi, Y., Fujimoto, M., Matsushita, T., Kaji, K., Komura, K., Hasegawa, M., et al. Common and distinct clinical features in adult patients with anti-aminoacyl-tRNA synthetase antibodies: Heterogeneity within the syndrome. PLoS ONE [Internet]. 2013 [cited 2014 Aug 21]; 8(4).

[47] Hervier, B., Devilliers, H., Stanciu, R., Meyer, A., Uzunhan, Y., Masseau, A., et al. Hierarchical cluster and survival analyses of antisynthetase syndrome: Phenotype and outcome are correlated with anti-tRNA synthetase antibody specificity. Autoimmun Rev. 2012; 12(2): 210-217.

[48] Marie, I., Josse, S., Hatron, P. Y., Dominique, S., Hachulla, E., Janvresse, A., et al. Interstitial lung disease in anti-Jo1 patients with antisynthetase syndrome. Arthritis Care Res. 2013; 65(5): 800-808.

[49] Marie, I., Lahaxe, L., Benveniste, O., Delavigne, K., Adoue, D., Mouthon, L., et al. Long-term outcome of patients with polymyositis/ dermatomyositis and anti-PM-Scl antibody. Br J Dermatol. 2010; 162(2): 337-344.

[50] Douglas, W. W., Tazelaar, H. D., Hartman, T. E., Hartman, R. P., Decker, P. A., Schroeder, D. R., et al. Polymyositisdermatomyositis-associated interstitial lung disease. Am J Respir Crit Care Med. 2001; 164(7): 1182-1185.

[51] Tillie-Leblond, I., Wislez, M., Valeyre, D., Crestani, B., Rabbat, A., Israel-Biet, D., et al. Interstitial lung disease and anti-Jo-1 antibodies: Difference between acute and gradual onset. Thorax. 2008; 63(1): 53-59.

[52] Hervier, B., Meyer, A., Dieval, C., Uzunhan, Y., Devilliers, H., Launay, D., et al. Pulmonary hypertension in antisynthetase syndrome: Prevalence, aetiology and survival. Eur Respir J. 2013; 42(5): 1271-1282.

[53] Ghillani, P., André, C., Toly, C., Rouquette, A. M., Bengoufa, D., Nicaise, P., et al. Clinical significance of anti-Ro52 (TRIM21) antibodies non-associated with anti-SSA 60kDa antibodies: Results of a multicentric study. Autoimmun Rev. 2011; 10(9): 509-513.

[54] Marie, I., Hatron, P. Y., Dominique, S., Cherin, P., Mouthon, L., Menard, J. -F., et al. Short-term and long-term outcome of anti-Jo1-positive patients with anti-Ro52 antibody. Semin Arthritis Rheum. 2012; 41(6): 890-899.

[55] Rigolet, A., Musset, L., Dubourg, O., Maisonobe, T., Grenier, P., Charuel, J. L., et al. Inflammatory myopathies with anti-Ku antibodies: A prognosis dependent on associated lung disease. Med Baltim. 2012; 91(2): 95-102.

[56] Fiorentino, D., Chung, L., Zwerner, J., Rosen, A., CasciolaRosen, L. The mucocutaneous and systemic phenotype of dermatomyositis patients with antibodies to MDA5 (CADM- 
140): A retrospective study. J Am Acad Dermatol. 2011; 65(1): 25-34.

[57] Gunawardena, H., Wedderburn, L. R., Chinoy, H., Betteridge, Z. E., North, J., Ollier, W. E. R., et al. Autoantibodies to a 140$\mathrm{kd}$ protein in juvenile dermatomyositis are associated with calcinosis. Arthritis Rheum. 2009; 60(6): 1807-1814.

[58] Ceribelli, A., Fredi, M., Taraborelli, M., Cavazzana, I., Franceschini, F., Quinzanini, M., et al. Anti-MJ/NXP-2 autoantibody specificity in a cohort of adult Italian patients with polymyositis/dermatomyositis. Arthritis Res Ther. 2012; 14(2): R97.

[59] Aguila, L. A., Lopes, M. R. U., Pretti, F. Z., Sampaio-Barros, P. D., Carlos de Souza, F. H., Borba, E. F., et al. Clinical and laboratory features of overlap syndromes of idiopathic inflammatory myopathies associated with systemic lupus erythematosus, systemic sclerosis, or rheumatoid arthritis. Clin Rheumatol. 2014; 33(8): 1093-1098.

[60] Koenig, M., Fritzler, M. J., Targoff, I. N., Troyanov, Y., Senecal, J. L. Heterogeneity of autoantibodies in 100 patients with autoimmune myositis: Insights into clinical features and outcomes. Arthritis Res Ther. 2007; 9(4): R78.

[61] Suzuki, S., Hayashi, Y. K., Kuwana, M., Tsuburaya, R., Suzuki, N., Nishino, I. Myopathy associated with antibodies to signal recognition particle: Disease progression and neurological outcome. Arch Neurol. 2012; 69(6): 728-732.

[62] Armour, R., Zhou, L. Outcomes of statin myopathy after statin withdrawal. J Clin Neuromuscul Dis. 2013; 14(3): 103-109.

[63] Mammen, A. L., Pak, K., Williams, E. K., Brisson, D., Coresh, J., Selvin, E., et al. Rarity of anti-3-hydroxy-3-methylglutarylcoenzyme A reductase antibodies in statin users, including those with self-limited musculoskeletal side effects. Arthritis Care Res Hoboken. 2012; 64(2):269-272.

[64] Torres, C., Belmonte, R., Carmona, L., Gómez-Reino, F. J., Galindo, M., Ramos, B., et al. Survival, mortality and causes of death in inflammatory myopathies. Autoimmunity. 2006; 39(3): 205-215.

[65] Fujisawa, T., Suda, T., Nakamura, Y., Enomoto, N., Ide, K., Toyoshima, M., et al. Differences in clinical features and prognosis of interstitial lung diseases between polymyositis and dermatomyositis. J Rheumatol. 2005; 32(1): 58-64.

[66] Woo, J. -H., Kim, Y. J., Kim, J. J., Choi, C. -B., Sung, Y. -K., Kim, T. -H., et al. Mortality factors in idiopathic inflammatory myopathy: Focusing on malignancy and interstitial lung disease. Mod Rheumatol Jpn Rheum Assoc. 2013; 23(3): 503-508.

[67] Yu, K. -H., Wu, Y. -J. J., Kuo, C. -F., See, L. -C., Shen, Y. -M., Chang, H. -C., et al. Survival analysis of patients with dermatomyositis and polymyositis: Analysis of 192 Chinese cases. Clin Rheumatol. 2011; 30(12): 1595-1601.

[68] Rigolet, A., Musset, L., Dubourg, O., Maisonobe, T., Grenier, P., Charuel, J. L., et al. Inflammatory myopathies with anti-Ku antibodies: A prognosis dependent on associated lung disease. Med Baltim. 2012; 91(2): 95-102.

[69] Zahr, Z. A., Baer, A. N. Malignancy in myositis. Curr Rheumatol Rep. 2011; 13(3): 208-215.

[70] Targoff, I. N., Mamyrova, G., Trieu, E. P., Perurena, O., Koneru, B., O'Hanlon, T. P., et al. A novel autoantibody to a 155 -kd protein is associated with dermatomyositis. Arthritis Rheum. 2006; 54(11): 3682-3689.

[71] Trallero-Araguás, E., Rodrigo-Pendás, J. Á., SelvaO'Callaghan, A., Martínez-Gómez, X., Bosch, X., Labrador-Horrillo, M., et al. Usefulness of anti-p155 autoantibody for diagnosing cancer-associated dermatomyositis: A systematic review and meta-analysis. Arthritis Rheum. 2012; 64(2): 523-532.
[72] Fiorentino, D. F., Chung, L. S., Christopher-Stine, L., Zaba, L., Li, S., Mammen, A. L., et al. Most patients with cancerassociated dermatomyositis have antibodies to nuclear matrix protein NXP-2 or transcription intermediary factor $1 \gamma$. Arthritis Rheum. 2013; 65(11): 2954-2962.

[73] Ichimura, Y., Matsushita, T., Hamaguchi, Y., Kaji, K., Hasegawa, M., Tanino, Y., et al. Anti-NXP2 autoantibodies in adult patients with idiopathic inflammatory myopathies: Possible association with malignancy. Ann Rheum Dis. 2012; 71(5): 710-713.

[74] Yamasaki, Y., Yamada, H., Yamasaki, M., Ohkubo, M., Azuma, K., Matsuoka, S., et al. Intravenous cyclophosphamide therapy for progressive interstitial pneumonia in patients with polymyositis/dermatomyositis. Rheumatol Oxf Engl. 2007; 46(1): 124-130.

[75] Kotani, T., Takeuchi, T., Makino, S., Hata, K., Yoshida, S., Nagai, K., et al. Combination with corticosteroids and cyclosporin-A improves pulmonary function test results and chest HRCT findings in dermatomyositis patients with acute/subacute interstitial pneumonia. Clin Rheumatol. 2011; 30(8): 1021-1028

[76] Takada, K., Nagasaka, K., Miyasaka, N. Polymyositis/dermatomyositis and interstitial lung disease: A new therapeutic approach with T-cell-specific immunosuppressants. Autoimmunity. 2005; 38(5): 383-392.

[77] Ando, M., Miyazaki, E., Yamasue, M., Sadamura, Y., Ishii, T., Takenaka, R, et al. Successful treatment with tacrolimus of progressive interstitial pneumonia associated with amyopathic dermatomyositis refractory to cyclosporine. Clin Rheumatol. 2010; 29(4): 443-445.

[78] Gheita, T. A., Gheita, H. A., Kenawy, S. A. Rituximab restored the muscle power and rescued from a refractory fatal respiratory failure in a patient with elderly-onset polymyositis. Jt Bone Spine Rev Rhum. 2012; 79(1): 101-102.

[79] Gono, T., Sato, S., Kawaguchi, Y., Kuwana, M., Hanaoka, M., Katsumata, Y., et al. Anti-MDA5 antibody, ferritin and IL-18 are useful for the evaluation of response to treatment in interstitial lung disease with anti-MDA5 antibody-positive dermatomyositis. Rheumatol Oxf. 2012; 51(9): 1563-1570.

[80] Stone, K. B., Oddis, C. V., Fertig, N., Katsumata, Y., Lucas, M., Vogt, M., et al. Anti-Jo-1 antibody levels correlate with disease activity in idiopathic inflammatory myopathy. Arthritis Rheum. 2007; 56(9): 3125-3131.

[81] Benveniste, O., Drouot, L., Jouen, F., Charuel, J. L., BlochQueyrat, C., Behin, A., et al. Correlation of anti-signal recognition particle autoantibody levels with creatine kinase activity in patients with necrotizing myopathy. Arthritis Rheum. 2011; 63(7): 1961-1971.

[82] Werner, J. L., Christopher-Stine, L., Ghazarian, S. R., Pak, K. S., Kus, J. E., Daya, N. R., et al. Antibody levels correlate with creatine kinase levels and strength in anti-HMG-CoA reductase-associated autoimmune myopathy. Arthritis Rheum [Internet]. 2012; Available from: http://www.ncbi.nlm.nih.gov/pubmed/22933019

[83] Oddis, C. V., Reed, A. M., Aggarwal, R., Rider, L. G., Ascherman, D. P., Levesque, M. C., et al. Rituximab in the treatment of refractory adult and juvenile dermatomyositis and adult polymyositis: A randomized, placebo-phase trial. Arthritis Rheum. 2013; 65(2): 314-324.

[84] Aggarwal, R., Bandos, A., Reed, A. M., Ascherman, D. P., Barohn, R. J., Feldman, B. M., et al. Predictors of clinical improvement in rituximab-treated refractory adult and juvenile dermatomyositis and adult polymyositis: Clinical and serologic predictors of improvement in myositis. Arthritis Rheumatol. 2014; 66(3): 740-749. 
[85] Bozkirli, D. E. E., Kozanoglu, I., Bozkirli, E., Yucel, E. Antisynthetase syndrome with refractory lung involvement and myositis successfully treated with double filtration plasmapheresis. J Clin Apheresis. 2013; 28(6): 422-425.

[86] Arlet, J. B., Dimitri, D., Pagnoux, C., Boyer, O., Maisonobe T., Authier, F. J., et al. Marked efficacy of a therapeutic strategy associating prednisone and plasma exchange followed by rituximab in two patients with refractory myopathy associated with antibodies to the signal recognition particle (SRP). Neuromuscul Disord. 2006; 16(5): 334-336.

[87] Dalakas, M. C. Mechanistic effects of IVIg in neuroinflammatory diseases: Conclusions based on clinicopathologic correlations. J Clin Immunol. 2014; 34(Suppl 1): S120-S126.

[88] Choy, E. H., Hoogendijk, J. E., Lecky, B., Winer, J. B., Gordon, P. WITHDRAWN: Immunosuppressant and immunomodulatory treatment for dermatomyositis and polymyositis. Cochrane Database Syst Rev. 2009; (4): CD003643.

[89] Kazuki, T., Bookbinder, S., Furie, R. A pilot study of eculizumab in patients with dermatomyositis. Arthritis Res Ther. 2002; 46(S489).

[90] Pestronk, A. Acquired immune and inflammatory myopathies: Pathologic classification. Curr Opin Rheumatol. 2011; 23(6): 595-604.

[91] Labrador-Horrillo, M., Martinez, M. A., Selva-O'Callaghan, A., Delgado, J. F., Martínez-Gómez, X., Trallero-Araguás, E., et al. Anti-cyclic citrullinated peptide and anti-keratin antibodies in patients with idiopathic inflammatory myopathy. Rheumatol Oxf Engl. 2009; 48(6): 676-679. 